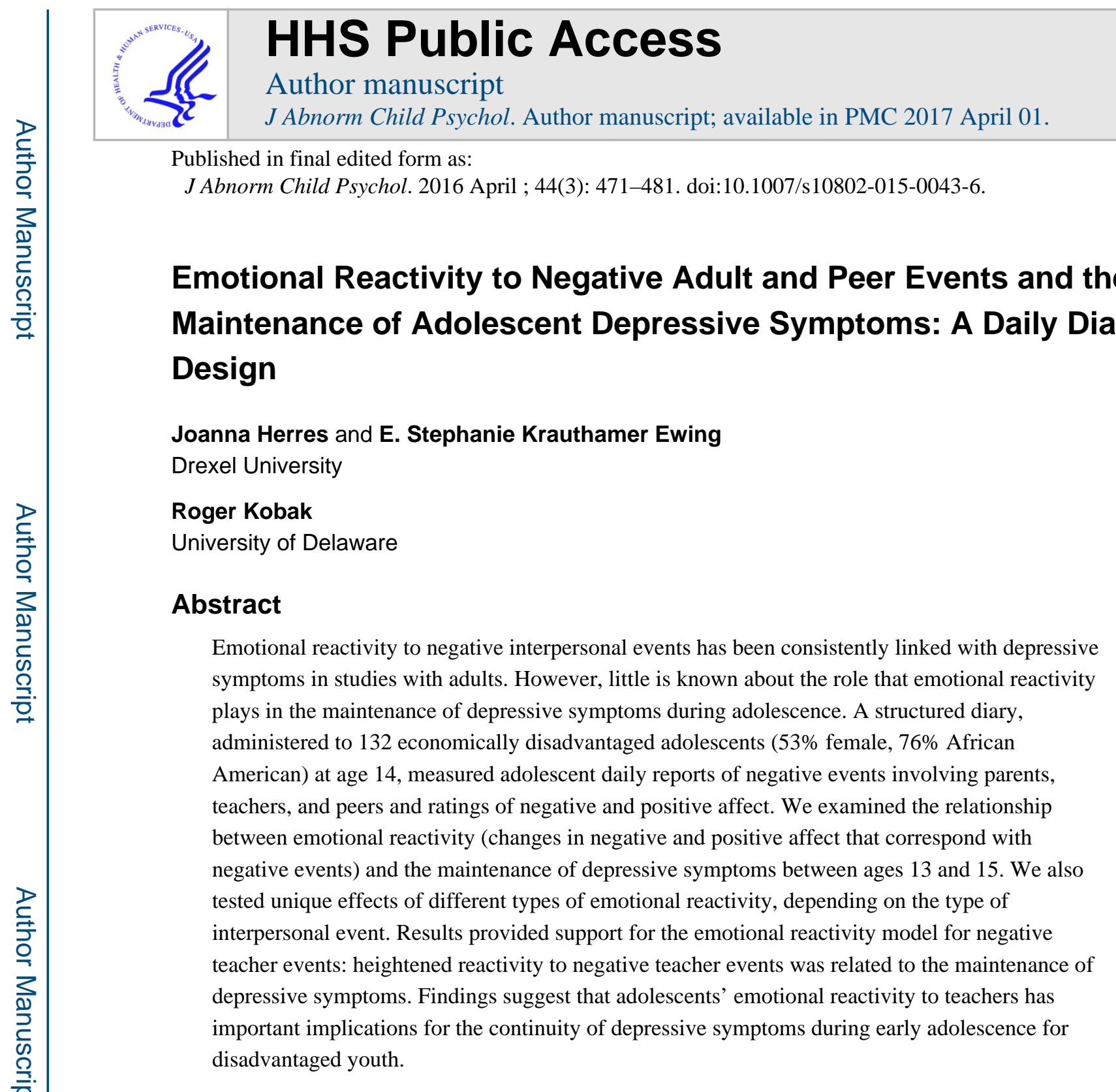

\title{
Keywords
}

adolescent depression; emotional reactivity; interpersonal events; daily diary

\begin{abstract}
A growing body of research suggests that individuals who experience more intense emotional reactions to negative interpersonal events are at increased risk for depressive symptomatology (Charbonneau, Mezulis, \& Hyde, 2009; Felsten, 2002). In spite of substantial evidence that high emotional reactivity (large emotional reactions to negative events) is implicated in depressive symptoms, few studies have examined the role that emotional reactivity plays in the maintenance of depressive symptoms, and even fewer have examined relations between emotional reactivity and depressive symptoms during early adolescence, a time period in which depressive symptoms stabilize and become more
\end{abstract}

Correspondence concerning this article should be addressed to Joanna Herres, Couple and Family Therapy Department, Drexel University, Philadelphia, PA 19104. (570)-447-7186. Contact: Joanna.L.Herres@drexel.edu. 
persistent (Hankin et al., 1998; Lewinsohn, Rohde, Klein, \& Seeley, 1999; McLaughlin \& King, 2015).

\section{Stress Exposure and Depression}

Two decades of research has examined effects of exposure to daily stressors, or negative events (Compas, Howell, Phares, Williams, \& Ledoux, 1989; Wagner, Compas, \& Howell, 1988).For example, Sim (2000) showed that daily hassles, such as being picked on by a peer or getting into an argument with a parent, predicted depressive symptoms. Daily hassles refer to negative experiences that occur over the course of a typical day. Although these experiences are often normative, they constitute threats to the emotional well-being of some individuals. Negative interpersonal events have been consistently identified as both antecedents and sequalae of adolescent depressive symptoms. Rudolph, Flynn, Abaied, Groot, and Thompson (2009) examined a transactional model of depression and found that stressful interpersonal events mediated increases in adolescent depressive symptoms over a 2 year time period for at-risk females. In a model that compared exposure to negative adult and peer events, Herres and Kobak (2014) found that negative peer events uniquely accounted for the maintenance of depressive symptoms across ages 13 to 15 for both males and females. Although these studies demonstrate important links between negative interpersonal events and depression over time, they fail to consider whether emotional reactions to events better account for the continuity of depressive symptoms than sheer exposure to events.

\section{Emotional Reactivity}

The emotional reactivity model posits that individuals who report larger emotional responses to negative events are more vulnerable to depressive symptoms (Gable, Reis, \& Elliot, 2000; Suls, Green, \& Hillis, 1998; van Eck, Nicolson, \& Berkhof, 1998). An association between emotional reactivity to interpersonal stress and depressive symptoms has been consistently reported in samples of college students and adults (Cohen, Gunthert, Butler, O'Neill, \& Tolpin, 2005; Nezlek \& Plesko, 2003; Parrish, Cohen, \& Laurenceau, 2011; Wichers et al., 2009). Both greater negative emotional reactivity (greater increases in negative emotions) and greater positive emotional reactivity (greater decreases in positive emotions) have been associated with increased depression risk. For example, O'Neill, Cohen, Tolpin, and Gunthert (2004) found that adults who reported increases in negative affect (NA) and decreases in positive affect (PA) that coincided with reports of daily negative interpersonal events were more likely to develop depressive symptoms two years later. Further, emotional reactivity has been shown to predict treatment outcome (i.e., reduction in depressive symptoms) for adults participating in cognitive therapy (Gunthert, Cohen, Butler, \& Beck, 2005).

Studies of emotional reactivity and depressive symptoms in adolescents have produced inconsistent findings (e.g., Charbonneau, Mezulis, \& Hyde, 2009). Schneiders et al. (2006) reported increased emotional reactivity to negative events among adolescents with both internalizing and externalizing problems even after controlling for overall exposure to negative events. Similarly, a study that used observational measures of emotional reactivity 
also demonstrated a link between reactivity and depression during adolescence (Sheeber et al., 2012), with depressed adolescent's showing increases in dysphoric behavior during negative interactions with parents, while nondepressed adolescents did not demonstrate escalation in this type of behavior. However, this study may not entirely capture emotional reactivity, since what was coded was behavioral responses rather than self-reported affective experience. In contrast to the literature that suggests that depressed adolescents experience heightened emotional reactivity, other studies propose that depressed individuals show less intense emotional reactions to stimuli (Bylsma, Morris, \& Rottenberg 2008). Bylsma, Taylor-Clift, and Rottenberg (2011) emphasize that this "context insensitivity" model occurs when using non-interpersonal laboratory stimuli (e.g., emotional films or pictures, a loud noise, mental arithmetic tasks) that may capture aspects of emotional numbing or blunted emotional expression rather than an individual's emotional response to real life events. In general, the literature tends to converge in support of the emotional reactivity model of depressive symptoms.

\section{Interpersonal context of emotional reactivity}

Youth increase their emotional investment in interpersonal relationships during adolescence (Weinstein, Mermelstein, Hedeker, Hankin, \& Flay, 2006) in accordance with important neural developmental changes (Nelson, Leibenluft, McClure, \& Pine, 2005). Studies of emotional reactivity to interpersonal events have typically aggregated reports of events rather than distinguishing between events in different relationship domains (Bolger, DeLongis, Kessler, \& Schilling, 1989; Bolger \& Schilling, 1991; O’Neill et al., 2004). However, distinguishing between interactions with adults (parents and teachers) and peers becomes important during adolescence as the impact of peers on daily mood increases (Weinstein et al., 2006). Further, as affiliative and sexual behavioral systems increase motivation for engaging with peers (Kobak, Rosenthal, Zajac, \& Madsen, 2007), adolescents seek increased autonomy from parents and other adult figures. These changes are reflected in adolescents' tendency to generally experience more positive mood with peers and more negative mood with family (Larson \& Richards, 1991). Thus, adolescents may react to negative events with parents or teachers differently from how they react to negative events with peers. Taken together, studies suggest that it is important to distinguish adolescents' emotional reactivity with adults and peers and the effects of these different types of reactivity to the maintenance of depressive symptoms.

Gender may also moderate adolescents' emotional reactivity to interactions with adults and peers (Flook, 2011; Hankin, Mermelstein, \& Roesch, 2007; Larson \& Ham, 1993; Shih, Eberhart, Hammen, \& Brennan, 2006; Wagner \& Compas, 1990). Girls' increased reactivity to negative interpersonal events may explain their increased vulnerability to depressive symptoms beginning in adolescence (Charbonneau et al., 2009; Flook, 2011). These findings suggest that depressive symptoms are more likely to persist for adolescent girls due to heightened emotional sensitivity to interpersonal experiences.

\section{The Current Study}

The current study tested the association between emotional reactivity and the maintenance of depressive symptoms from early to mid-adolescence. We extended prior research by 
differentiating types of emotional reactivity across domains of interpersonal events (e.g., events involving parents, teachers, and peers). Building on the study design described in Herres and Kobak (2014), the current study examined the extent to which emotional reactivity to adult and peer events accounted for the maintenance of depressive symptoms while controlling for overall exposure to negative interpersonal events. We used depressive symptoms at age 13 to predict emotional reactivity at age 14 and emotional reactivity at age 14 to predict depressive symptoms at age 15 . Emotional reactivity was assessed at age 14 using a 2-week diary procedure to evaluate the unique effects of interactions with parents, teachers, and peers while controlling for adolescents' overall levels of mood and exposure to negative interpersonal events. Based on findings suggesting that girls show greater emotional reactivity to interpersonal events than boys (Charbonneau et al., 2009; Flook, 2011), we also tested gender as a moderator of the link between reactivity to negative events and the maintenance of depressive symptoms. We restricted the sample to adolescents from predominately low-income families in order to examine diversity among a socioeconomic group at risk for experiencing negative events and depressive symptoms (Eamon, 2001; Tracy, Zimmerman, Galea, McCauley, \& Vander Stoep, 2008).

\section{Method}

\section{Participants}

One hundred thirty-two adolescents (53\% female) were recruited from the first cohort of a two-cohort sample of 225 low-income families participating in a larger longitudinal study conducted in a small urban area of Delaware. Adolescents received $\$ 75$ for completing 2 weeks of diaries. Financial constraints required restricting the sample to the first cohort of the larger study. Means comparisons for the study variables yielded no significant differences between adolescents who participated in the diary assessments and those who did not. The mean annual family income was $\$ 25,500(S D=\$ 26,000)$. Seventy-six percent of the sample identified themselves as African American, 21\% Caucasian, and 3\% Hispanic.

\section{Procedures}

The age 13 and age 15 assessments took place in the adolescents' homes and schools. At age 14 , adolescents were interviewed by phone on 8 weekday evenings (Monday through Thursday) between the hours of 6 p.m. and 10 p.m. Consecutive administration on 8 weekday evenings spanned 2 consecutive weeks, which follows general guidelines regarding diary administration (Gunthert \& Wenze, 2012). According to Gunthert \& Wenze (2012), acceptable variability in events that occur on a daily basis (e.g., minor stressors) can be obtained over the course of 2 weeks. Interviews were conducted only on weekday evenings to allow participants to report on events that occurred in the school context and to maximize the likelihood of reaching participants at a consistent time each day. Responses to the diary questions reflected the verbatim responses of the participants. Questionnaires were administered over the phone rather than via the internet to increase rates of participation and reduce missing data. Interviews lasted approximately 15 minutes and were administered by trained undergraduate research assistants. If a participant could not be reached on a particular evening, interviewers continued to call on subsequent evenings until they 
completed all eight interviews. On average, all eight interviews were completed within 15 days $(S D=8$ days $)$.

\section{Measures of Depression}

Depressive Symptoms-Adolescents completed the Children's Depression Inventory (CDI; Kovacs, 1985) at the age 13 assessment and the Center for the Epidemiological Study of Depression Scale (CES-D; Radloff, 1977) at the age 15 assessment. The CDI includes 27 items consisting of groups of three statements that varied in level of severity (e.g., I am sad once in a while, I am sad many times, I am sad all the time) ( $\alpha=.82$ for this study). Participants indicated which statement best describes the way that they felt in the past 2 weeks. The CDI included items that assessed disturbed mood (e.g., "I feel like crying every day."), anhedonia (e.g., "Nothing is fun at all."), vegetative functioning (e.g., "I am tired all the time."), and interpersonal problems (e.g., "I get into fights all the time."). The item pertaining to suicidal ideation was removed from the measure at the request of the Institutional Review Board (IRB). The CES-D ( $\alpha=.84$ for this study) consisted of 20 items in which participants rated how often they experienced symptoms associated with depression, such as restless sleep, poor appetite, and feeling lonely during the past week. Response options ranged from 0 (Rarely or none of the time) to 3 (Most or almost all the time).

Self-Esteem-The Rosenberg Self-Esteem Scale (Rosenberg, 1965) is a widely used measure of self-value and self-respect that has good construct, convergent, and discriminant validity (Crandal, 1973). The scale's ten items are rated from 1 (Strongly Disagree) to 9 (Strongly Agree), and a total scale score was computed by averaging across items. Internal consistency for the sample (measured by Cronbach's alpha) was .85 .

Hopelessness-The Hopelessness Scale (Kazdin, Rodgers, \& Colbus, 1986) assesses negative future expectancies. Participants rated 17 items as either True or False. The scale demonstrated an internal consistency for the sample of .77. The scale is highly correlated with measures of depressive symptoms (Kazdin et al., 1986).

\section{Latent Depression Scale}

In order to account for the difference in depressive symptoms measures across the two time points, latent variables combined scores from the depression scales with scores from the Hopelessness Scale and Rosenberg's Self-Esteem Scale measured at both time points. The self-esteem variable was reverse-coded so that the metric was consistent with the other two scales (higher scores on the new self-esteem variable coincided with higher depression scores). Multiple studies support the convergent validity of the CES-DC and CDI for adolescents with large concurrent correlations between the two scales $(r=.61, N=148$ in Faulstich, Carey, Ruggiero, Enyart, \& Gresham, 1987; $r=.58, N=1039$ in Doerfler, Felnder, Rowlison, Raley, \& Evans, 1988). However, because it was important that the relationship between age 13 and age 15 symptoms not be attenuated due to a lack of measurement invariance across the two scales, we combined information from the hopelessness and self-esteem scales to produce a more trait-like estimate of depressive tendencies. Including these scales improved stability in measurement over time ( $r$ for the 
latent depression variables $=.59, p<.01)$. Further, the latent variables represented Beck's negative cognitive triad (Beck, 1967), which includes negative views of the self (low selfesteem), the world (general depressive symptoms), and the future (hopelessness) (see Herres \& Kobak, 2014).

\section{Diary Measures}

Daily affect ratings-Four items from the Sadness subscale (sad, blue, downhearted, and alone) and five items from the Positive Affect scale (interested, determined, enthusiastic, excited, and inspired) of the Positive and Negative Affect Schedule (PANAS; Watson \& Clark, 1992) assessed adolescent's daily negative affect (NA) and positive affect (PA) on a 1 (strongly disagree) to 5 (strongly agree) scale regarding how they felt that day. Item scores were averaged to calculate a daily negative affect score. The item lonely was excluded from the NA scale based on results of a multilevel factor analysis showing redundancy between this item and the item "alone." Participants rated these items on a scale from 1 (strongly disagree) to 5 (strongly agree) regarding their feelings on the day of the interview. The NA and PA scales have demonstrated good convergent and discriminant validity (Watson \& Clark, 1992) and showed good internal consistency in the current sample ( $\mathrm{a}$ for NA $=.84$; $\mathrm{a}$ for $\mathrm{PA}=.86$ ).

Daily event checklist-Participants rated an events checklist to indicate the extent to which they had experienced particular daily events on a 1 (not at all) to 4 (a lot) scale (Herres \& Kobak, 2014). The checklist was an expanded version used in previous studies (Little \& Kobak, 2003; Esposito, Kobak, \& Little, 2005). The following items were used in the current study: 4 negative parent events (You talked back to a parent; You were yelled at by a parent; You argued with a parent; Your parent cursed at you; $a=.76$ ); 3 negative peer events (You got into a fight with another kid; You argued with another kid; Another kid disrespected you; $\alpha=.74$ ); and 4 negative teacher events (You got in trouble with a teacher; You received a detention; A teacher got mad at you; You got a warning from a teacher; $a=$. 76).

\section{Control Measures}

Family income-to-needs ratio-The income-to-needs ratio reflected per capita family income divided by the per capita figure constituting the federal poverty standard for the assessment year. At the age 13 assessment, caregivers provided estimates of total household income earned from employment of all residents and income derived from other sources (i.e., disability, child support, public assistance, retirement, etc.). A ratio of 1.0 represents the poverty line and a ratio of 2.0 represents the threshold for economic disadvantage. The mean was $1.27(S D=.99)$ and the median was 1.15 . Forty-four percent of the sample had ratios below the poverty line.

Family risk index-The family risk index (Ackerman \& Brown, 2006) reflected caregiver responses at the age 13 assessment wave to questions about five markers of family risk experienced in the previous 2 years. For each marker, we coded affirmative answers 1 and negative answers 0 and summed the scores to form an index. The markers reflected mother reports about (a) whether she experienced any changes in intimate residential partners 
(32\%); (b) whether the household experienced any change in residence (36\%); (c) whether any adult member of the household had police contact for criminal behavior (15\%); (d) whether any adult member of the household was under psychiatric treatment (20\%); and (e) whether any adult member of the household experienced drug or alcohol dependence or abuse $(17 \%)$. The index mean was $1.17(S D=1.06)$. Among these markers, only change in residence and change in mother's intimate residential partners correlated significantly, $r=$. $24, p<.01$.

\section{Results}

We first present descriptive statistics and zero-order correlations among the observed predictor and outcome variables. We then summarize results of multilevel structural equation models tested using Mplus Version 7.0 (Muthén \& Muthén, 1998-2012) to account for the clustering of repeated diary measures within subjects (Muthén \& Asparouhov, 2011). Within-subject reactivity indicated the Level 1 relationship between daily mood and daily events. Between-subject variability in the reactivity relationships was examined at Level 2. Model parameters were estimated using maximum likelihood estimation with robust standard errors (MLR). Maintenance of depressive symptoms was determined by the presence of a significant A path (reactivity regressed on age 13 depressive symptoms), a significant B path (age 15 depressive symptoms regressed on reactivity), and a significant coefficient corresponding to the product of the A and B paths, which was calculated using the NEW parameter option under the model constraint command in Mplus. Under a mediation framework, the product coefficient would correspond to an indirect effect; however, the model did not include an estimate of the $\mathrm{C}$ path found in traditional mediation models (in this case, the path linking age 13 and age 15 depressive symptoms).

\section{Preliminary analyses}

Descriptive statistics and zero-order correlations among the observed variables are shown in Table 1. Examination of distributional statistics indicated that many of the variables were skewed, and as a result, Log 10 transformations were used to establish normal distributions prior to subsequent analyses. Adolescent gender was not associated with differences in symptoms or diary measures. However, by age 15 , females reported slightly higher levels of depressive symptoms and lower levels of self-esteem than males. Because demographic variables were not correlated with the other study variables, they were not included as covariates in subsequent analyses. Paired samples t-tests provided evidence of the stability of depressive symptoms in our sample: the means for the hopelessness, $t(95)=.11, \mathrm{p}=$ n.s. and self-esteem variables, $t(95)=.28, \mathrm{p}=n$.s., did not significantly differ across ages 13 and 15. The effect of reactivity on changes in depression was not evaluated due to the lack of variance in growth of depressive symptoms over the time period. Further evidence of the stability of the depression measures over time is described below.

A confirmatory factor analysis supported the construction of two latent depression variables using depressive symptoms, low self-esteem, and hopelessness as indicators of age 13 and age 15 depression (Herres \& Kobak, 2014) ${ }^{1}$. The model is depicted in Figure 1. Multiple group analysis of gender invariance did not reveal differences in the model across male and 
female participants. A full description of the measurement model and results of invariance tests can be found in Herres and Kobak (2014). The latent depression variables were stable across ages 13 to $15, r=.59, \mathrm{p}<.001$. Given the lack of variance in growth of depression, we considered the effects of emotional reactivity on the maintenance of depression, rather than on changes in depression over this time period.

\section{Emotional Reactivity Model}

The emotional reactivity model tested whether heightened emotional reactivity (both negative and positive reactivity) to negative daily events at age 14 was associated with the maintenance of depressive symptoms between ages 13 and 15 . Six reactivity variables were created at the within-subject level (Level 1) by regressing daily NA and PA on each of the three types of daily negative events (parent, teacher, and peer). The event variables were group-mean centered so that the within-subject mean for each subject was equal to zero. The intraclass correlations (ICC), which reflect the amount of variance in each variable accounted for by between-subject differences, were .37 for NA, .52 for PA, .31 for negative parent events, .34 for negative peer events, and .37 for negative teacher events.

Table 2 summarizes the fixed and random effects for the within-subject reactivity slopes. The fixed mean of the reactivity slopes indicates the average amount of emotional reactivity to daily events across all subjects, and the random variance component indicates the amount of between-subjects variability in the slopes. On average, adolescents reported significant increases in NA on days when they experienced higher levels of negative parent and peer events. Fixed, or average, effects for PA reactivity to the three types of negative events were not significant. Examination of random effects indicated that only the slope for NA reactivity to negative parent events showed significant between-subjects variability. However, even when random effects are not significant, it is still possible for betweensubject covariates (e.g., level of depressive symptoms) to significantly influence the reactivity slopes if power to detect these effects increases by adding covariates to the model.

Between-subjects random effects in the six reactivity slopes were tested for a) whether they were predicted by levels of depressive symptoms at age 13 (the A path); b) whether they predicted depressive symptoms at age 15 (the B path); and c) whether the indirect effect of emotional reactivity made a significant contribution to the maintenance of depressive symptoms. Models were tested separately for each type of reactivity to negative events and included controls for average levels of NA and exposure to daily events (the conceptual model is shown in Figure 2). Results of these tests are summarized in Table 3. NA reactivity to negative teacher events produced significant direct and indirect effects (Figure 3). This finding indicates that adolescents who reported heightened NA response to negative teacher events were more likely to maintain increased depressive symptoms across ages 13 to 15 . PA reactivity to negative teacher events and PA reactivity to negative parent events

\footnotetext{
${ }^{1}$ Due to possible concerns with overlapping content of the depression and negative interpersonal events scales, the depression variables were reconstructed after two items were removed from the CDI and two items were removed from the CESD (e.g., People were unfriendly). The old and new variables were correlated $r=.99$ at both time points and study results were unchanged with the use of the new variables.
} 
produced trends for the A path, trends for the B path, and significant indirect effects. Effects were not significant for NA and PA reactivity to negative peer events.

\section{Gender Moderation of the Reactivity Models}

Finally, gender was tested as a moderator of the emotional reactivity models. Multiple group analyses examined whether there were significant decreases in model fit after applying cross-group equality constraints by using changes in the loglikelihood value (Yuan and Bentler, 2000). Before examining gender differences in the structural paths between the reactivity slopes and the latent depression variables, we first examined moderation of the within-subject reactivity slopes. These analyses indicated significant gender differences in both NA reactivity to negative teacher events, $\Delta \mathrm{X}^{2}(1)=7.12, p<.01$, and PA reactivity to negative teacher events, $\Delta \mathrm{X}^{2}(1)=4.29, p<.05$. Males reported larger increases in NA and larger decreases in PA in response to negative teacher events, $\beta$ for NA $=0.181, p<.01 ; \beta$ for $\mathrm{PA}=-0.163, p<.05$, while females did not report significant changes in mood following negative teacher events, $\beta$ for NA $=-0.067, p=.21 ; \beta$ for $\mathrm{PA}=0.06, p=.48$. This finding cannot be attributed to gender differences in exposure to negative teacher events, $r=.06, p=$ n.s. Next, we examined whether gender moderated the relationship between the betweensubject reactivity slope variables and the latent depression variables. None of these analyses were significant, indicating that the strength of the relationship between reactivity and depression did not differ for males and females. Given the relatively small group sizes (62 females and 70 males), it is possible that the current study lacked statistical power to detect gender differences in the structural paths (though there was sufficient power to detect gender differences in the within-subject relationships between mood and events).

\section{Discussion}

Although study design did not allow us to test reactivity as a causal mechanism that maintains depression over time, the findings support the link between emotional reactivity to negative events and the maintenance of depressive symptoms between early to midadolescence. As expected, on average, participants reported increases in NA in response to negative parent and peer events; however, mood responses to daily events varied between adolescents as a function of their depressive symptoms. Exploration across interpersonal domains found that more depressed adolescents showed unique emotional reactions to negative teacher events, with trends for reactivity to negative parent events. Examination of gender moderation did not reveal gender differences in the relationships between reactivity and depression. Overall, the findings suggest that reactivity to negative adult events play an important role in the maintenance of adolescents' depressive symptoms.

Support for the emotional reactivity model is consistent with the view that early adolescence is a period of heightened emotional sensitivity to interpersonal events (Larson \& Richards, 1991; Rudolph \& Hammen, 1999; Steinberg \& Morris, 2001) and that this enhanced sensitivity plays a role in adolescent depressive symptomatology (e.g., Pine, Cohen, \& Brook, 2001; Steinberg, 2005). Previous studies have examined the role of negative events in the maintenance of adolescent depression (Herres \& Kobak, 2014, Rudolph et al., 2009). While there is strong support for the role of negative events in adolescent depression, results 
from the current study suggest that heightened reactivity to negative events, particularly negative interactions with adults, and not just the sheer exposure to events, is associated with the maintenance of depressive symptoms during early adolescence. These findings are consistent with the idea that depressed adolescents have more difficulty regulating or modulating their emotional reactions to daily interpersonal situations (Gross, 2011). The specificity of the finding for reactivity to teacher interactions may be a function of specific developmental considerations, including the importance of autonomy development and academic competence to self-worth during adolescence. Rogers' (1961) theory of self-worth (Nezlek \& Gable, 2001) further helps to put these results into a developmental context.

\section{Self-Worth}

The current findings further specify that depressed adolescents are more reactive to a particular domain of interpersonal events (e.g., teachers vs. peer events). Crocker and Wolfe (2001) describe how the relative salience of events for an individual results, at least in part, from the degree to which an individual's self-worth is contingent on a particular domain. From this perspective, negative interactions with teachers may be particularly salient to adolescents as an indicator of their future success in the world outside their families. Negative interactions with teachers may signal more general disengagement from school and increased risk for problem behaviors such as sexual risk taking (Kobak, Herres, Gaskins, \& Laurenceau, 2012). As a result, depressed adolescents may view negative teacher interactions as particularly relevant to a negative view of their future success.

Depressed adolescents' fluctuations in self-esteem (e.g., Costello, Benjamin, Angold, \& Silver, 1991; Gable \& Nezlek, 1998; Kuppens, Van Mechelen, Nezlek, Dossche, \& Timmermans, 2007) may lower their thresholds for reacting to daily interpersonal events. Nezlek and Gable (2001) ascribe a Rogerian framework to explain the increased emotional reactivity of depressed individuals. They posit that depressed individuals may experience stronger affective responses to events that are more likely to threaten their self-worth (Nezlek \& Gable, 2001). Contingencies of self-worth fluctuate across development and reflect changes in one's goals. Emotions are goal-directed, and emotional reactivity may fluctuate with the development of new interpersonal goals during adolescence, such as the desire to establish autonomy from adult authority figures (e.g., Allen, Hauser, Bell, \& O'Connor, 1994). As a result, negative interactions with authority figures are likely to be perceived as threats to autonomy and lead to strong emotional reactions that coincide with persistent depressive symptoms. Sensitivity to self-worth contingencies and evolving interpersonal goals are potential explanations for why depressed individuals show stronger affective responses to negative interactions with adults.

\section{Strengths, Limitations, and Future Directions}

Our findings extend previous research in several ways. Although studies support an association between emotional reactivity and adult depression (e.g., Cohen, et al., 2005; Nezlek \& Plesko, 2003), few studies have examined this association during adolescence, a critical developmental period marked by increased vulnerability to interpersonal experiences and the emergence of persistent depressive symptoms. Further, many studies view emotional reactivity as either an antecedent or sequalae of depressive symptoms. By contrast, the 
longitudinal study design combined both pathways, which allowed us to examine the relationship between emotional reactivity and the maintenance of depressive symptoms across a 2 year span. Further, the findings yielded new information about the specific types of interpersonal events to which depressed adolescents are most reactive.

In spite of the study's strengths, the generalizability of the findings is limited in several respects. It is possible that the findings would not hold in a sample of adolescents from more economically diverse families or in a clinical sample of adolescents who meet diagnostic criteria for a depressive disorder (only $10 \%$ of the current sample reported symptoms above the clinical cutoff score of 19 for the CDI; Kovacs, 1985). The small sample size may not be capable of detecting gender differences in the maintenance of adolescent depressive symptoms (Hankin et al., 1998). Although the longitudinal design addressed emotional reactivity as a factor that maintains depressive symptoms, we cannot make claims regarding causal relationships. Many of the processes examined in this study may be bidirectional; for example, daily mood may influence daily interpersonal interactions. Further, although the use of a daily diary design decreased risk of retrospective bias associated with recalling daily events, future studies that utilize more frequent measurement, such as ecological momentary assessment, would eliminate concerns regarding this possible bias. Replication of the study findings would strengthen support for the unique effects of reactivity to negative teacher events. Finally, the study measures were limited to self-report. It is possible that we would have obtained different results had we included other informants, such as teachers and parents, or if we had used laboratory procedures with discrete stressors. Future research should examine the convergent validity of different indices of emotional reactivity (e.g., models of emotional reactivity based on behavioral vs. self-report measures). In addition, research examining neurological pathways associated with emotional reactivity may help identify important biomarkers associated with the maintenance of depressive symptoms during adolescence.

Changes in levels of neurotransmitters in the limbic system during adolescence are associated with increased vulnerability to both social interactions and depression (Nelson et al., 2005). Studies examining the neural development of adolescents suggest that psychopathology may develop during this time period due to problems associated with the social information processing network (SIPN) in the brain, which is involved in emotional attributes applied to social stimuli. The SIPN has been implicated in the development and maintenance of mood disorders, and studies suggest that changes in the SIPN during adolescence lead to more intense affective responses to interpersonal events (Nelson et al., 2005). Thus, increased sensitivity to interpersonal events in accordance with heightened levels of depressive symptoms may result from neural developmental changes occurring during adolescence. Future studies should compare differences in the neural development of adolescents lower and higher in depressive symptoms to potentially explain why more depressed adolescents show increased sensitivity to interpersonal events.

The study examined changes in daily mood that fluctuated in response to events experienced during the same day, rather than sustained emotional responses. Examination of relations between emotional reactivity and other aspects of emotion dysregulation, such as emotional inertia (i.e., the degree to which a person's current emotional state is predicted by their prior 
emotional state), warrants future study (Kuppens, Allen, \& Sheeber, 2010; Kuppens et al., 2012; Thompson et al., 2012). Additionally, although heightened reactivity to interpersonal events may increase risk for the development and maintenance of depressive symptoms, blunted emotional reactivity may be evident as an immediate response to an environmental stimulus. Continuing to compare reactivity to different types of events might further differentiate ways that daily experiences influence depressive symptoms. For example, the current study did not examine reactivity to positive events. Future studies might also include the examination of other possible moderators of the reactivity/depression link, such as trait PA (Nezlek \& Plesko, 2003), emotion knowledge, and emotion utilization (Izard, Stark, Trentacosta, \& Schultz, 2008).

The current findings may have implications for identifying at-risk youth, as well as for improving and/or refining depression treatments. For example, depressed individuals may benefit from improved awareness of their susceptibility to intense emotional reactivity to interpersonal events, and targeted interventions could focus on modulating the effects of heightened mood reactivity. Such targeted interventions might focus on improving awareness of mood reactivity, conscious efforts to modulate reactivity (e.g., relaxation exercises, coping strategies), and helping at-risk individuals learn better strategies to harness the adaptive and motivational energy of specific emotions (e.g., noticing sadness reactions and reaching out for effective social support). Empirically supported treatments, such as Dialectical Behavioral Therapy, target emotional reactivity as part of efforts to improve overall emotion regulation. Further studies are needed to explicitly examine whether changes in emotional reactivity directly or indirectly impact treatment outcome.

\section{Acknowledgements}

We thank the members of the Parent Teen Project for their help with data collection. This research was supported by a grant from the National Institute of Mental Health (RO1-MH59670, to Roger Kobak). There are no known conflicts of interest associated with this publication and there has been no significant financial support for this work that could have influenced its outcome.

\section{References}

Ackerman BP, Brown ED. Income poverty, poverty co-factors, and the adjustment of children in elementary school. Advances in Child Development and Behavior. 2006; 34:91-129. [PubMed: 17120803]

Allen JP, Hauser ST, Bell KL, O'Connor TG. Longitudinal assessment of autonomy and relatedness in adolescent family interactions as predictors of adolescent ego development and self-esteem. Child Development. 1994; 65:179-194. [PubMed: 8131646]

Beck, AT. Depression: Clinical, experimental, and theoretical aspects. Harper \& Row; New York: 1967.

Bolger N, De Longis A, Kessler RC, Schilling EA. Effects of daily stress on negative mood. Journal of Personality and Social Psychology. 1989; 57:808-818. [PubMed: 2810026]

Bolger N, Schilling EA. Personality and the problems of everyday life: The role of neuroticism in exposure and reactivity to daily stressors. Journal of Personality. 1991; 59:355-383. [PubMed: 1960637]

Bylsma LM, Morris BH, Rottenberg J. A meta-analysis of emotional reactivity in major depressive disorder. Clinical Psychology Review. 2008; 28:676-691. [PubMed: 18006196]

Bylsma L, Taylor-Clift A, Rottenberg J. Emotional reactivity to daily events in major and minor depression. Journal of Abnormal Psychology. 2011; 120:155-167. [PubMed: 21319928] 
Charbonneau A, Mezulis A, Hyde JS. Stress and emotional reactivity as explanations for gender differences in adolescents' depressive symptoms. Journal of Youth and Adolescence. 2009; 38:1050-1058. [PubMed: 19636770]

Cohen LH, Gunthert K, Butler A, O’Neill S, Tolpin L. Daily affective reactivity as a prospective predictor of depressive symptoms. Journal of Personality. 2005; 73:1687-1713. [PubMed: 16274450]

Compas BE, Howell DC, Phares V, Williams RA, Ledoux N. Parent and child stress and symptoms: An integrative analysis. Developmental Psychology. 1989; 25:550-559.

Costello EJ, Benjamin R, Angold A, Silver D. Mood variability in adolescents: A study of depressed, nondepressed and comorbid patients. Journal of Affective Disorders. 1991; 23:199-212. [PubMed: 1791265]

Crandal R. The measurement of self-esteem and related constructs. Measures of Social Psychological Attitudes. 1973; 45:167.

Crocker J, Wolfe CT. Contingencies of self-worth. Psychological Review. 2001; 108:593-623. [PubMed: 11488379]

Eamon MK. The effects of poverty on children's socioemotional development: An ecological systems approach. Social Work. 2001; 46:256-266. [PubMed: 11495370]

Esposito AJ, Kobak R, Little M. Aggression and self-esteem: A diary study of children's reactivity to negative interpersonal events. Journal of Personality. 2005; 73:887-906. [PubMed: 15958138]

Carey MP, Faulstich ME, Gresham FM, Ruggiero L, Enyart P. Children's Depression Inventory: Construct and discriminant validity across clinical and nonreferred (control) populations. Journal of Consulting and Clinical Psychology. 1987; 55:755. [PubMed: 3454787]

Felsten G. Minor stressors and depressed mood: Reactivity is more strongly correlated than total stress. Stress and Health. 2002; 18:75-81.

Flook L. Gender differences in adolescents' daily interpersonal events and well-being. Child Development. 2011; 82:454-461. [PubMed: 21410907]

Gable SL, Nezlek JB. Level and instability of day-to-day psychological well-being and risk for depression. Journal of Personality and Social Psychology. 1998; 74:129-138. [PubMed: 9457778]

Gable SL, Reis HT, Elliot AJ. Behavioral activation and inhibition in everyday life. Journal of Personality and Social Psychology. 2000; 78:1135-1149. [PubMed: 10870914]

Gross, JJ. Handbook of emotion regulation. Guilford Press; 2011.

Gunthert K, Cohen L, Butler A, Beck J. Predictive role of daily coping and affective reactivity in cognitive therapy outcome: Application of a daily process design to psychotherapy research. Behavior Therapy. 2005; 36:79-90.

Gunthert, KC.; Wenze, SJ. Daily diary methods. In: Mehl, MR.; Conner, TS., editors. Handbook of research methods for studying daily life. Guilford Press; New York, NY: 2012. p. 144-159.

Hankin BL, Abramson LY, Moffitt TE, Silva PA, McGee R, Angell KE. Development of depression from preadolescence to young adulthood: Emerging gender differences in a 10-year longitudinal study. Journal of Abnormal Psychology. 1998; 107:128-140. [PubMed: 9505045]

Hankin BL, Mermelstein R, Roesch L. Sex differences in adolescent depression: Stress exposure and reactivity models. Child Development. 2007; 78:279-295. [PubMed: 17328705]

Herres J, Kobak R. The role of parent, teacher, and peer events in maintaining depressive symptoms during early adolescence. Journal of Abnormal Child Psychology. 2014:1-13. [PubMed: 24272365]

Izard CE, Stark K, Trentacosta C, Schultz D. Beyond emotion regulation: Emotion utilization and adaptive functioning. Child Development Perspectives. 2008; 2:156-163. [PubMed: 19956781]

Kazdin AE, Rodgers A, Colbus D. The Hopelessness Scale for Children: Psychometric characteristics and concurrent validity. Journal of Consulting and Clinical Psychology. 1986; 54:241-245. [PubMed: 3700812]

Kobak R, Herres J, Gaskins C, Laurenceau JP. Teacher-student interactions and attachment states of mind as predictors of early romantic involvement and risky sexual behaviors. Attachment \& human development. 2012; 14:289-303. [PubMed: 22537525] 
Kobak R, Rosenthal NL, Zajac K, Madsen SD. Adolescent attachment hierarchies and the search for an adult pair bond. New Directions for Child and Adolescent Development. 2007; 2007; 117:57742. [PubMed: 17876788]

Kobak R, Herres J, Gaskins C, Laurenceau J-P. Teacher-student interactions and attachment states of mind as predictors of early romantic involvement and risky sexual behaviors. Attachment \& Human Development. 2012; 14:289-303. [PubMed: 22537525]

Kovacs M. The Children's Depression Inventory (CDI). Psychopharmacology Bulletin. 1985; 21:995998. [PubMed: 4089116]

Kuppens P, Allen NB, Sheeber LB. Emotional inertia and psychological maladjustment. Psychological Science. 2010; 21:984-991. [PubMed: 20501521]

Kuppens P, Sheeber LB, Yap MBH, Whittle S, Simmons JG, Allen NB. Emotional inertia prospectively predicts the onset of depressive disorder in adolescence. Emotion. 2012; 12:283289. [PubMed: 21988744]

Kuppens P, Van Mechelen I, Nezlek JB, Dossche D, Timmermans T. Individual differences in core affect variability and their relationship to personality and psychological adjustment. Emotion. 2007; 7:262-274. [PubMed: 17516805]

Larson R, Ham M. Stress and "storm and stress" in early adolescence: The relationship of negative events with dysphoric affects. Developmental Psychology. 1993; 29:130-140.

Larson R, Richards MH. Daily companionship in late childhood and early adolescence: Changing developmental contexts. Child Development. 1991; 62:284-300. [PubMed: 2055123]

Lewinsohn PM, Rohde P, Klein DN, Seeley JR. Natural course of adolescent major depressive disorder: Continuity into young adulthood. Journal of the American Academy of Child \& Adolescent Psychiatry. 1999; 38:56-63. [PubMed: 9893417]

Little M, Kobak R. Emotional security with teachers and children's emotional reactivity: A comparison of special-education and regular-education classrooms. Journal of Clinical Child and Adolescent Psychology. 2003; 32:127-138. [PubMed: 12573938]

McLaughlin KA, King K. Developmental trajectories of anxiety and depression in early adolescence. Journal of Abnormal Child Psychology. 2014; 43:311-323. [PubMed: 24996791]

Muthén, B.; Asparouhov, T. Beyond multilevel regression modeling: Multilevel analysis in a general latent variable framework. In: Hox, J.; Roberts, JK., editors. Handbook of Advanced Multilevel Analysis. Taylor and Francis; New York: 2011.

Muthén, LK.; Muthén, BO. Mplus User's Guide. Sixth. Muthén \& Muthén; Los Angeles, CA: 1998-2010.

Nelson EE, Leibenluft E, McClure EB, Pine DS. The social re-orientation of adolescence: A neuroscience perspective on the process and its relation to psychopathology. Psychological Medicine. 2005; 35:163-174. [PubMed: 15841674]

Nezlek JB, Gable SL. Depression as a moderator of relationships between positive daily events and day-to-day psychological adjustment. Personality and Social Psychology Bulletin. 2001; 27:16921704.

Nezlek JB, Plesko RM. Affect and self-based models of relationships between daily events and daily well-being. Personality and Social Psychology Bulletin. 2003; 29:584-596. [PubMed: 15282906]

Nolen-Hoeksema S. Responses to depression and their effects on the duration of depressive episodes. Journal of Abnormal Psychology. 1991; 100:569-582. [PubMed: 1757671]

O'Neill SC, Cohen LH, Tolpin LH, Gunthert KC. Affective reactivity to daily interpersonal stressors as a prospective predictor of depressive symptoms. Journal of Social and Clinical Psychology. 2004; 23:172-194.

Parrish BP, Cohen LH, Laurenceau J-P. Prospective relationship between negative affective reactivity to daily stress and depressive symptoms. Journal of Social and Clinical Psychology. 2011; 30:270296.

Pine DS, Cohen P, Brook JS. Emotional reactivity and risk for psychopathology among adolescents. CNS Spectrum. 2001; 6:27-35.

Radloff LS. The CES-D scale: A self-report depression scale for research in the general population. Applied Psychological Measurement. 1977; 1:385-401. 
Rogers, C. On becoming a person: A therapist's view of psychotherapy. Houghton Mifflin; Boston, MA: 1961.

Rosenberg, M. Society and the adolescent self-image. Princeton University Press; Princeton, NJ: 1965.

Rudolph KD, Hammen C. Age and gender as determinants of stress exposure, generation, and reactions in youngsters: A transactional perspective. Child Development. 1999; 70:660-677. [PubMed: 10368914]

Rudolph KD, Flynn M, Abaied J, Groot A, Thompson R. Why is past depression the best predictor of future depression? Stress generation as a mechanism of depression continuity in girls. Journal of Child Clinical and Adolescent Psychology. 2009; 38:473-485.

Schneiders J, Nicolson NA, Berkhof J, Feron FJ, van Os J, deVries MW. Mood reactivity to daily negative events in early adolescence: Relationship to risk for psychopathology. Developmental Psychology. 2006; 42:543-554. [PubMed: 16756444]

Sheeber LB, Kuppens P, Shortt JW, Katz LF, Davis B, Allen NB. Depression is associated with the escalation of adolescents' dysphoric behavior during interactions with parents. Emotion. 2012; 12:913. [PubMed: 22023365]

Shih JH, Eberhart N, Hammen C, Brennan PA. Differential exposure and reactivity to interpersonal stress predict sex differences in adolescent depression. Journal of Clinical Child and Adolescent Psychology. 2006; 35:103-115. [PubMed: 16390306]

Sim H. Relationship of daily hassles and social support to depression and antisocial behavior among early adolescents. Journal of Youth and Adolescence. 2000; 29:647-659.

Steinberg L. Cognitive and affective development in adolescence. Trends in Cognitive Science. 2005; 9:69-74.

Steinberg L, Morris AS. Adolescent development. Annual Review of Psychology. 2001; 52:83-110.

Suls J, Green P, Hillis S. Emotional reactivity to everyday problems, affective inertia, and neuroticism. Personality and Social Psychology Bulletin. 1998; 24:127-136.

Thompson RJ, Mata J, Jaeggi SM, Buschkuehl M, Jonides J, Gotlib IH. The everyday emotional experience of adults with major depressive disorder: Examining emotional instability, inertia, and reactivity. Journal of Abnormal Psychology. 2012; 121:819-29. doi. 10.1037/a0027978. [PubMed: 22708886]

Tracy M, Zimmerman FJ, Galea S, McCauley E, Vander Stoep A. What explains the relation between family poverty and childhood depressive symptoms? Journal of Psychiatric Research. 2008; 42:1163-1175. [PubMed: 18308337]

van Eck M, Nicolson NA, Berkhof J. Effects of stressful daily events on mood states: Relationship to global perceived stress. Journal of Personality and Social Psychology. 1998; 75:1572-1585. [PubMed: 9914667]

Wagner BM, Compas BE. Gender, instrumentality, and expressivity: Moderators of adjustment to stress during adolescence. American Journal of Community Psychology. 1990; 18:383-406. [PubMed: 2264556]

Wagner BM, Compas BE, Howell DC. Daily and major life events: A test of an integrative model of psychosocial stress. American Journal of Community Psychology. 1988; 16:189-205. [PubMed: 3407632]

Watson D, Clark LA. On traits and temperament: General and specific factors of emotional experience and their relation to the five-factor model. Journal of Personality. 1992; 60:441-476. [PubMed: 1635050]

Weinstein SM, Mermelstein RJ, Hedeker D, Hankin BL, Flay BR. The time-varying influences of peer and family support on adolescent daily positive and negative affect. Journal of Clinical Child and Adolescent Psychiatry. 2006; 35:420-430.

Wichers M, Geschwind N, Jacobs N, Kenis G, Peeters F, Derom C, et al. Transition from stress sensitivity to a depressive state: Longitudinal twin study. British Journal of Psychiatry. 2009; 195:498-503. [PubMed: 19949197]

Yuan K, Bentler PM. Three likelihood-based methods for mean and covariance structure analysis with nonnormal missing data. Sociological Methodology. 2000; 30:167-202. 


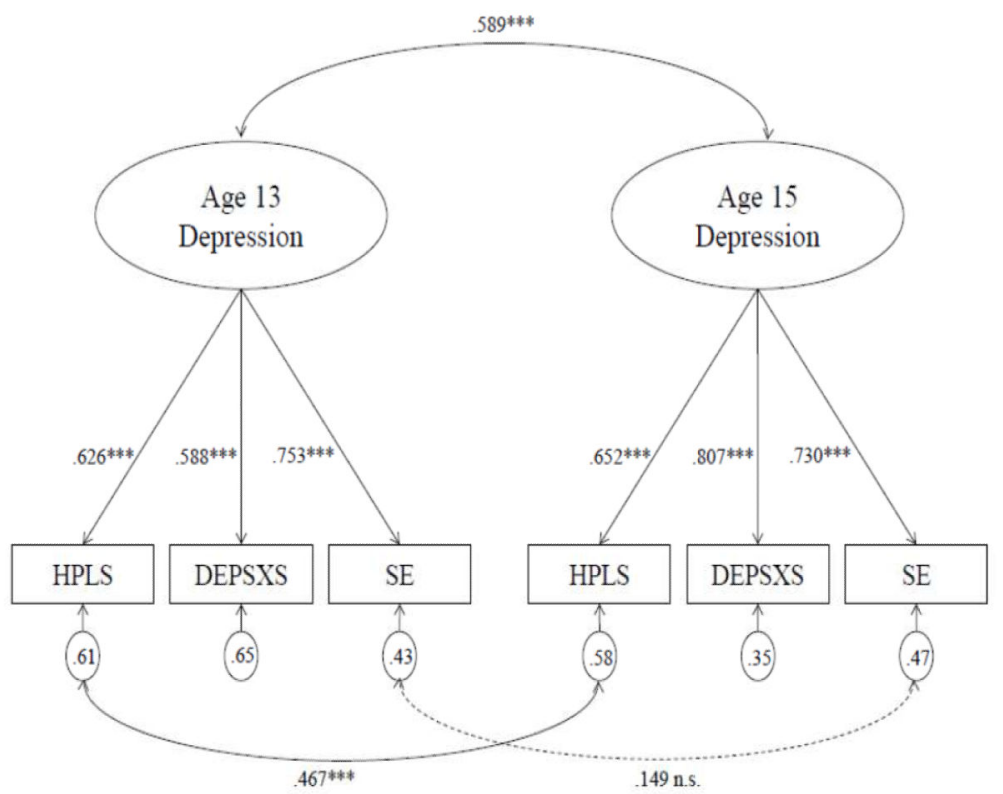

Figure 1.

Standardized parameter estimates for the measurement of latent depression variables. HPLS $=$ Hopelessness, DEPSXS = Depressive Symptoms, SE = Self-Esteem. 
$\underline{\text { Age } 13}$

Age 14

$\underline{\text { Age } 15}$

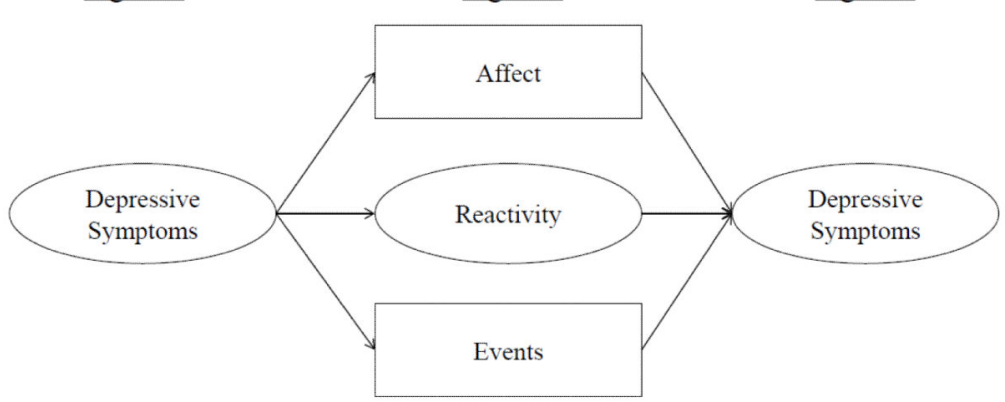

Figure 2.

Hypothetical reactivity model in which emotional reactivity to events maintains depressive symptoms across ages 13 to 15 after controlling for average level of affect and events. Emotional reactivity is a latent variable representing between-subject variability in the within-subject relationships between daily affect and daily events. 


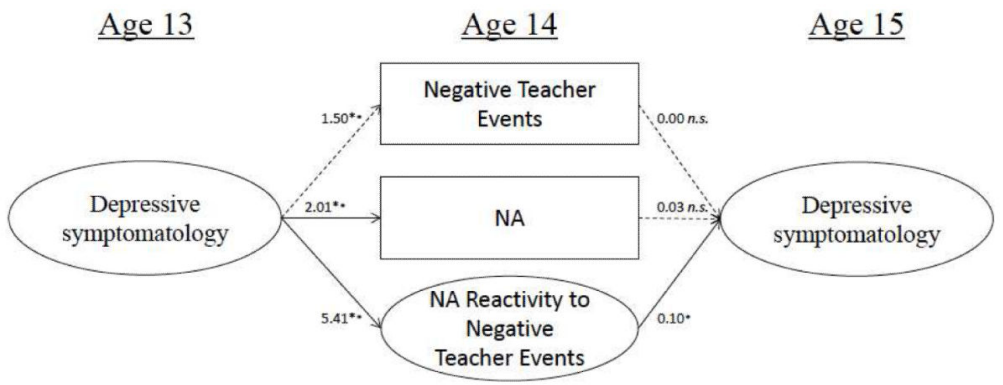

Figure 3.

Emotional reactivity model in which NA reactivity to negative teacher events maintains depressive symptoms across ages 13 to 15 after controlling for average level of negative affect (NA) and negative teacher events. 


\section{Table 1}

Descriptive Statistics and Zero-Order Correlations ( $\mathrm{N}=132)$ among Study Variables

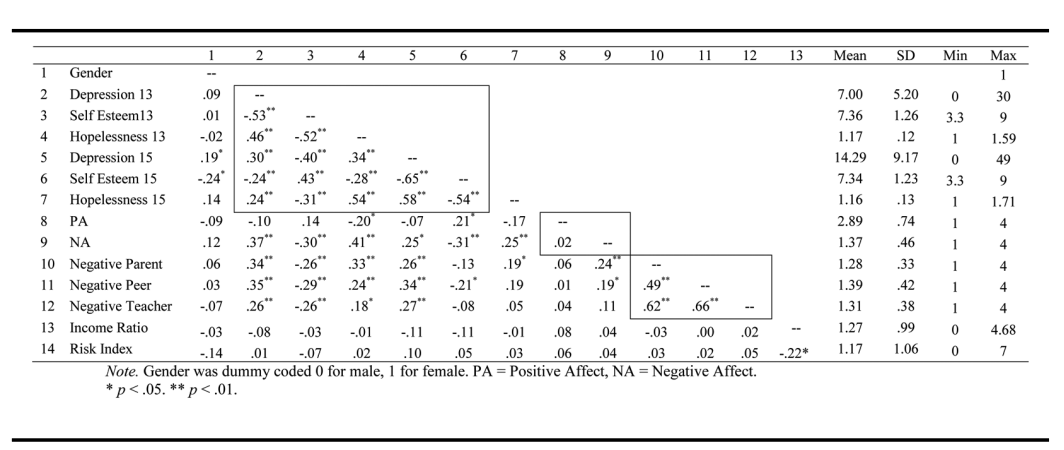

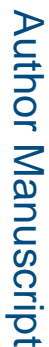

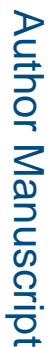

를

J Abnorm Child Psychol. Author manuscript; available in PMC 2017 April 01. 
Table 2

Within-Person Relationships between Daily Events and Daily Negative (NA) and Positive (PA) Affect (N = 132)

\begin{tabular}{lllll}
\hline & \multicolumn{2}{c}{ NA } & \multicolumn{2}{c}{$\underline{\text { PA }}$} \\
& Mean & Variance & Mean & Variance \\
\hline Negative Parent & $0.274^{* * *}$ & $0.155^{* *}$ & $-0.096^{\dagger}$ & 0.015 \\
Negative Peer & $0.102^{*}$ & 0.028 & -0.032 & 0.027 \\
Negative Teacher & 0.053 & 0.036 & -0.056 & 0.034 \\
\hline
\end{tabular}

Note. Coefficients are unstandardized.

${ }^{\dagger} p<.1$.

* $p<.05$.

$* *$ p $<.01$

**** $p<.001$. 


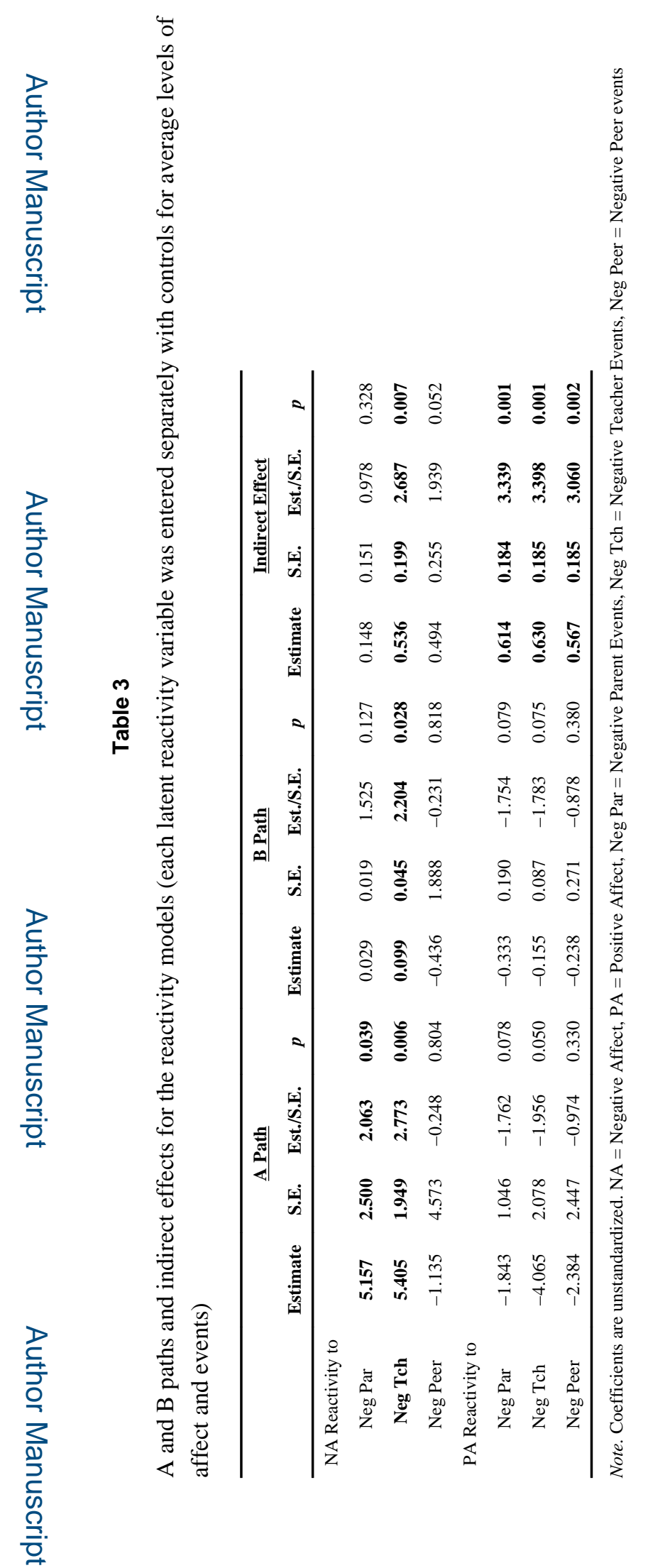

J Abnorm Child Psychol. Author manuscript; available in PMC 2017 April 01. 